\title{
Home-made software development for optimizing the uncertainty evaluation of silver fixed point cell used for practical realization of ITS-90
}

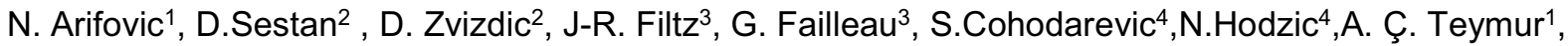 \\ N. Jandric ${ }^{4}$, S. Simic ${ }^{5}$, D. MacLochlainn ${ }^{6}$, J. Bojkovski $^{7}$, J. Drnovsek $^{7}$ \\ ${ }^{1}$ Turkiye Bilimsel ve Teknolojik Arastirma Kurumu, Gebze Yerleşkesi, 41470 Gebze/Kocaeli, Turkey \\ ${ }^{2}$ Fakultet strojarstva i brodogradnje, Ulica Ivana Lučića 5, 10000, Zagreb, Croatia \\ ${ }^{3}$ Laboratoire national de métrologie et d'essais, 29, Avenue Roger Hennequin, 78190 Trappes, France \\ ${ }^{4}$ Institut za mjeriteljstvo Bosne i Hercegovine, Augusta Brauna br.2, 71000 Sarajevo, Bosna i Hercegovina \\ ${ }^{5} \mathrm{MoE}$ - Directorate of measures and precious metals, Mike Alasa 14, 11000 Belgrade, Republic of Serbia \\ ${ }^{6}$ National Standards Authority of Ireland, Griffith Avenue Extension, Glasnevin, Dublin 9, Ireland. \\ 7 Univerza v Ljubljani, Kongresni trg 12, 1000 Ljubljana, Slovenia
}

\begin{abstract}
In order to enhance the availability of facilities in the field of high temperature contact thermometry in European emerging National Metrology Institutes (NMIs) and Designated Institutes (DIs), where access to types of facilities is currently limited an EMPIR Research Potential Project named EuraThermal has been launched. This project develop skills and tools for less experienced NMIs/Dls in order to acquire the required knowledge and expertise in temperature metrology.

Within the frame of the work package dedicated to contact thermometry, the work is focused on the silver fixed point cell which is one of the fixed points defined by the International Temperature Scale of 1990 (ITS-90). In this way, the traceability for the practical realization of the kelvinin accordance with the International System of Units (SI) would be provided with the lowest uncertainties.

The home-made software has been developed in Lab View language which includes and standardizes the validated measurement procedure. Moreover, the software provides a practical tool for the evaluation of uncertainties according to the "Guide to the expression of uncertainty in measurements". This enables to quantifying the main component contribution on uncertainty budget during the realization of the Silver fixed point cell measurements.
\end{abstract}

Performance and usefulness of the software and evaluation of uncertainty will be discussed in this paper.

This work is funded through the European Metrology Programme for Innovation and Research (EMPIR) project "RPT05 - EuraThermal". EMPIR is jointly funded by the EMPIR participating countries within EURAMET and the European Union.

\section{Introduction}

The current International Temperature Scale of 1990 (ITS-90) is defined by means of platinum resistance thermometers calibrated at specified temperature fixed-points and by using interpolation procedures at temperatures between the triple point of hydrogen $(13.8033 \mathrm{~K})$ and the freezing point of silver $\left(961.78^{\circ} \mathrm{C}\right)$ [1]. Above the triple point of water, metal melting or freezing transitions are used as calibration points for Standard Platinum Resistance Thermometers (SPRTs).In the temperature range between the freezing temperatures of aluminium and silver, special High Temperature Standard Platinum Resistance Thermometers (HTSPRTs) are used to realize the ITS-90 [2].

Within the scope of the EuraThermal project, LabView software was developed that enables recording and graphical representation of instrument readings, regardless of the quantities measured by an instrument.

(C) The Authors, published by EDP Sciences. This is an open access article distributed under the terms of the Creative Commons Attribution 
At the moment, practically every instrument used in the thermometry laboratories of Project participants uses data acquisition software that was supplied together with an instrument, or it was custom made by the laboratory. As a consequence, the users are required to learn to operate a different software for each instrument or to develop a new custom software. Many of those solutions have different graphic user interfaces, different ways of data representation as well as various formats for acquired data storage. The participants to the Project recognized the following benefits of having a new data acquisition software that would be unique for all the instruments used for the particular measurements:

1. Common graphic user interface leads to reduction or complete avoidance of the learning time required for the user to be able to operate the software,

2. Common format for data storage simplifies the data analysis using spreadsheet software,

3. Implementation of a new instrument to the base code is relatively simple as the software core handles the graphical data representation and storage,

4. Possible simultaneous logging of data from different instruments by opening several instances of the same program, as shown in Fig 1.,

5. Program instances can communicate to enable calculation of desired parameters based on the readings from different instruments.

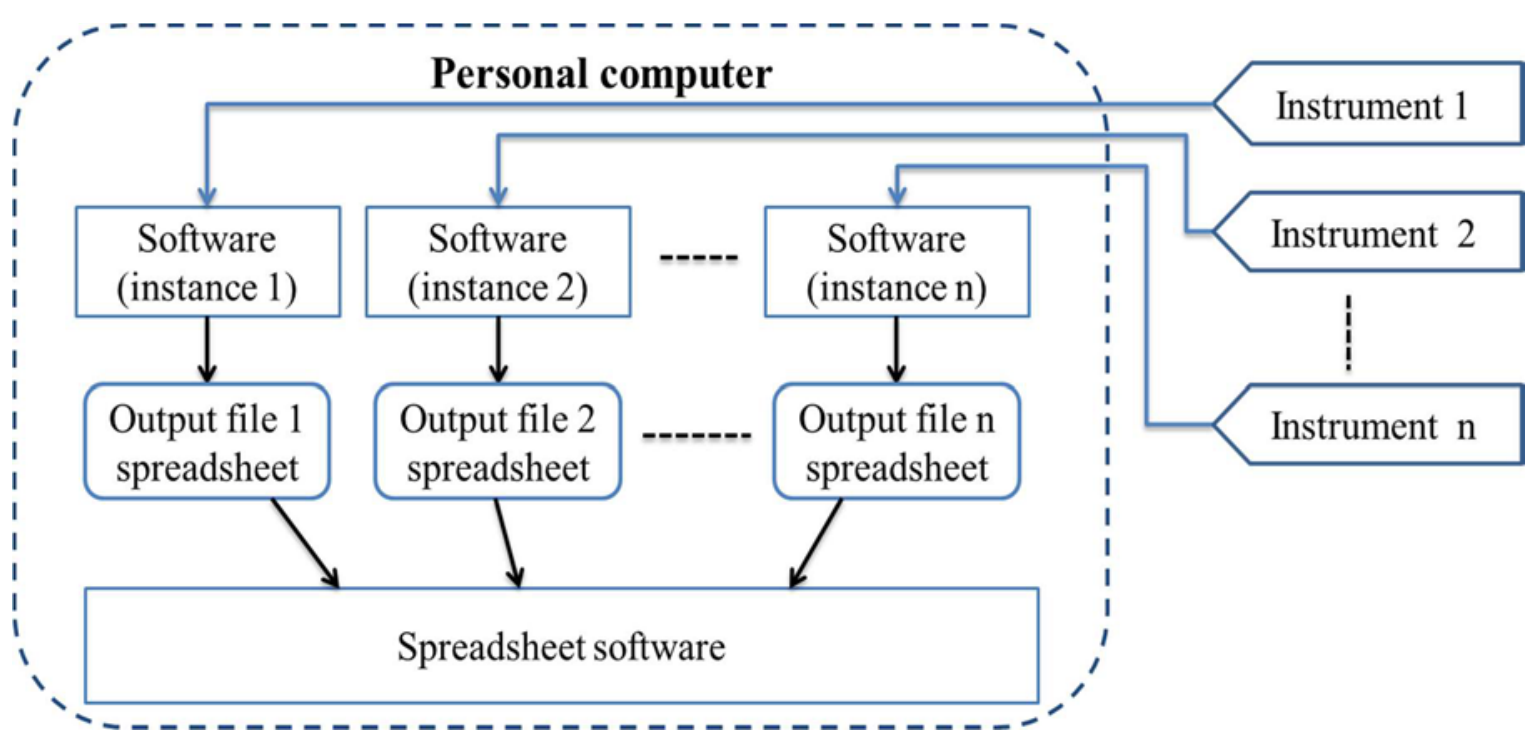

Figure 1. The main software concept for enabling simultaneous logging of data from different instruments.

In general, the base of the software enables the user to:

1. Select the desired instrument to be logged from the menu containing all the instruments available

2. Select the data to be read, when an instrument supports measurement of different quantities (for example multimeter can measure voltage, current, electrical resistance, etc.)

3. Adjust the scanner (multiplexor) reading sequence and type of reading at particular channel, if selected type of instrument supports it

4. Set the calculations that will be performed, based on the readings and additional parameters (for example, a resistance thermometry bridge shows the ratio of resistances of the thermometer and standard resistor, based on the known resistance of the standard resistor and known thermometer characteristics, the software can calculate the temperature measured)

5. Set the time interval between subsequent instrument readings

6. Save the readings and calculated data to the spreadsheet file 
7. Track the desired readings and calculations in time on the same or separate graph windows, where time window can be easily adjusted.

\section{The software algorithm}

The simplified software algorithm is graphically presented in Fig. 2. The software starts by reading the initialization file and adjusting the settings to the same state as they were during its last use. The information about the particular setting is stored in the initialization file as soon as the user makes the change(i.e. changes of the type of the instrument to be read, reading interval, settings for graphical representation of results, instrument settings, etc.).

The software enables the user to change the instrument settings. In order ensure that new instrument settings are effective after the change, the request is sent to the instrument to return the actual settings which are then compared to the desired ones.

The main logging loop takes care of setting the required scanner channel, pausing the loop for the period between readings set by the user and recording the last instrument reading to the computer memory. As soon as the new readings were taken from the instrument, software triggers start of subroutines for calculations, and graphical representation of the results and the loop starts again.

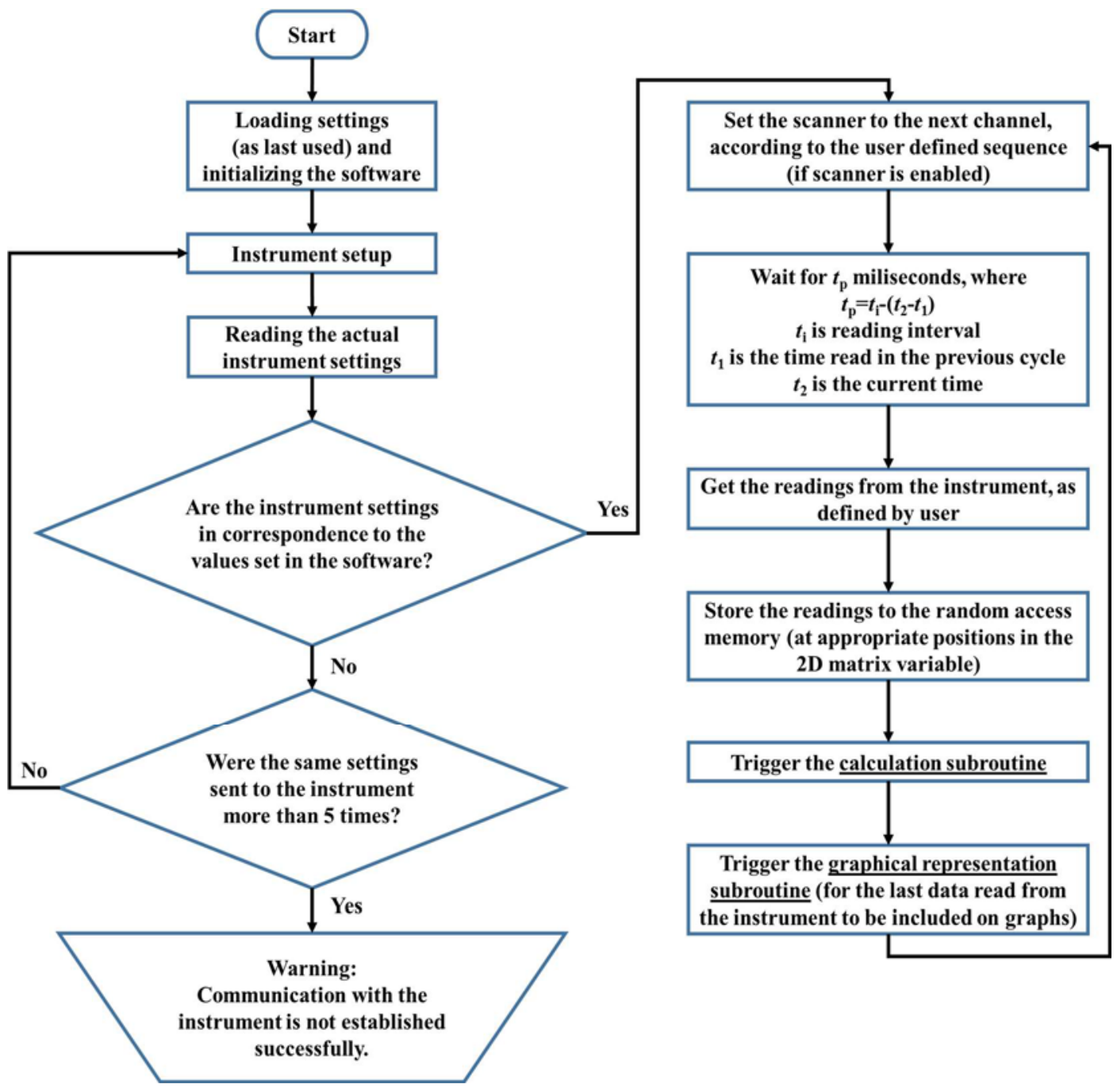

Figure 2. The flowchart showing the simplified software algorithm. 
As the Project participants work in the field of temperature measurements, software is currently supporting the calculations related to temperature measurement. In this case, the temperature is calculated based on the resistance readings obtained by using thermometry resistance bridges (for platinum resistance thermometers) or voltage readings obtained by using millivoltmeter (for thermocouples). The calculation subroutine is accessed from the main logging loop immediately after a new reading is taken from the instrument. Based on this reading and characteristic of the temperature sensor (or sensors if the scanneris used), the temperature is calculated and stored to the appropriate position in the data storage variable. The calculation subroutine then triggers the graphical representation subroutine, which immediately updates the appropriate graphic window to include the new data calculated. In order to be able to connect the particularly calculated values with the instrument characteristic and additional data used for the calculation, all the changes made to the calculation settings are registered in a separate variable and saved to the log file, together with the time of occurrence. Since data calculation and storage represents the last operation performed on the particular reading, this subroutine performs the task of synchronizing the data saving to the spreadsheet file, if saving is enabled.

The data is stored in the spreadsheet file in a format whose structure is represented in Fig. 3 . As can be seen, together with data measured/calculated, the spreadsheet file also contains the short description of the data used for making calculations. In the case of temperature measurement, its value will be calculated based on the characteristic of the thermometer connected to the bridge (possibly through the particular scanner channel). In this case, the short description will contain short thermometer designation, its calibration date, type of interpolation and valid temperature range for the chosen characteristic of the thermometer. In this way, the user is allowed to make the changes to the program settings while saving is active and those changes are later easy to track in the output file.

\begin{tabular}{|c|c|c|c|c|c|c|c|c|c|}
\hline CH1 & & & & & & & & $\mathrm{CH} 2$ & \\
\hline Date & Time & $\begin{array}{c}\text { Reading } \\
1\end{array}$ & ... & $\begin{array}{c}\text { Reading } \\
\text { n }\end{array}$ & $\begin{array}{c}\text { Calculated } \\
\text { value } 1\end{array}$ & ... & $\begin{array}{l}\text { Calculated } \\
\text { value } n\end{array}$ & Date & $\ldots$ \\
\hline \# & \# & & & & $\begin{array}{c}\text { Short } \\
\text { description of } \\
\text { data used for } \\
\text { calculation } 1\end{array}$ & & $\begin{array}{c}\text { Short } \\
\text { description } \\
\text { of data used } \\
\text { for } \\
\text { calculation } n\end{array}$ & $\#$ & ... \\
\hline \# & \# & $\#$ & ... & $\#$ & $\#$ & ... & $\#$ & $\#$ & ... \\
\hline$\#$ & $\#$ & $\#$ & $\ldots$ & $\#$ & $\#$ & $\ldots$ & $\#$ & $\#$ & $\ldots$ \\
\hline$\#$ & $\#$ & & $\ldots$ & & $\begin{array}{c}\text { New } \\
\text { description if } \\
\text { settings were } \\
\text { changed }\end{array}$ & $\ldots$ & $\begin{array}{c}\text { New } \\
\text { description if } \\
\text { settings were } \\
\text { changed }\end{array}$ & $\#$ & $\ldots$ \\
\hline \# & $\#$ & $\#$ & $\ldots$ & $\#$ & $\#$ & $\ldots$ & $\#$ & $\#$ & $\ldots$ \\
\hline
\end{tabular}

Figure 3. Representation of output spreadsheet file, containing the measurement data.

\subsection{Preliminary validation of the calculation subroutine}

The calculation subroutines related to measurements with thermocouples and platinum resistance thermometers are validated in Laboratory for process measurement (Croatia). The validation consisted of a comparison of the temperatures calculated using the software with those calculated by using other means. As the first calculation reference, the additional software is used, which was successfully 
validated in the process of laboratory accreditation. Those results were additionally confirmed by using the Excel based calculations as the validation reference. The comparison was performed for SPRTs calibrated according to the ITS-90in the following subranges: $-189.3442{ }^{\circ} \mathrm{C}$ to $0.01{ }^{\circ} \mathrm{C},-38.8344{ }^{\circ} \mathrm{C}$ to $29.7646{ }^{\circ} \mathrm{C}$ and $0.01{ }^{\circ} \mathrm{C}$ to $961.78{ }^{\circ} \mathrm{C}$ with the temperature step of $10{ }^{\circ} \mathrm{C}$. The temperatures calculated using both validation methods were matching to the less than $10^{-6} \mathrm{~K}$. For PRT's, the validation was performed using Callendar-Van Dusen equation, using standard coefficients according to the IEC 60751-2008standard, in the temperature range between $-100{ }^{\circ} \mathrm{C}$ to $660^{\circ} \mathrm{C}$. In this case, the results were matching to less than $10^{-3}{ }^{\circ} \mathrm{C}$. For the thermocouples types $\mathrm{S}$ and $\mathrm{K}$, the comparison was performed in the temperature ranges from $-50{ }^{\circ} \mathrm{C}$ to $1760{ }^{\circ} \mathrm{C}$ and $-270{ }^{\circ} \mathrm{C}$ to $1360{ }^{\circ} \mathrm{C}$ respectively, with the step of $50{ }^{\circ} \mathrm{C}$. The results were matching to less than $10^{-3}{ }^{\circ} \mathrm{C}$.

\subsection{The uncertainty evaluation module}

For the primary calibrations of HTSPRTs and Au/Pt thermocouples, the additional module was added to the software, enabling the user to automatically calculate the calibration uncertainty and generate the related uncertainty budget in the Excel format. To enable the module, the user is required to set the appropriate calibration type in the software and start measurement recording procedure. After the measurements are finished, the type A uncertainty is automatically calculated. All other uncertainties, related to the primary standard (fixed point cell) and equipment used (i.e. resistance bridge, millivoltmeter, calibration furnace,etc.) are derived from the database, containing the relevant uncertainty components. In this way, the user has the option to specify the equipment used and the software will add the related uncertainty components to the editable fields, whose values can be changed if required in particular situation. If required, the module also provides the possibility to name and enter the additional uncertainty components to the budget. After confirming the values by clicking on the appropriate button, the uncertainty budget is generated, whose Excel template was previously agreed between the Project participants.

\subsection{The graphic user interface}

The graphic user interface (GUI) is made in the following categories (Fig. 4 and Fig 5):

1. Instrument setup (Fig. 4)

2. Save setup

3. Calibration (for selecting type of calibration and used equipment)

4. Calculations (Fig. 5)

5. Graph

6. Graph $\times 3$ (for showing the data in three separate graph windows) 


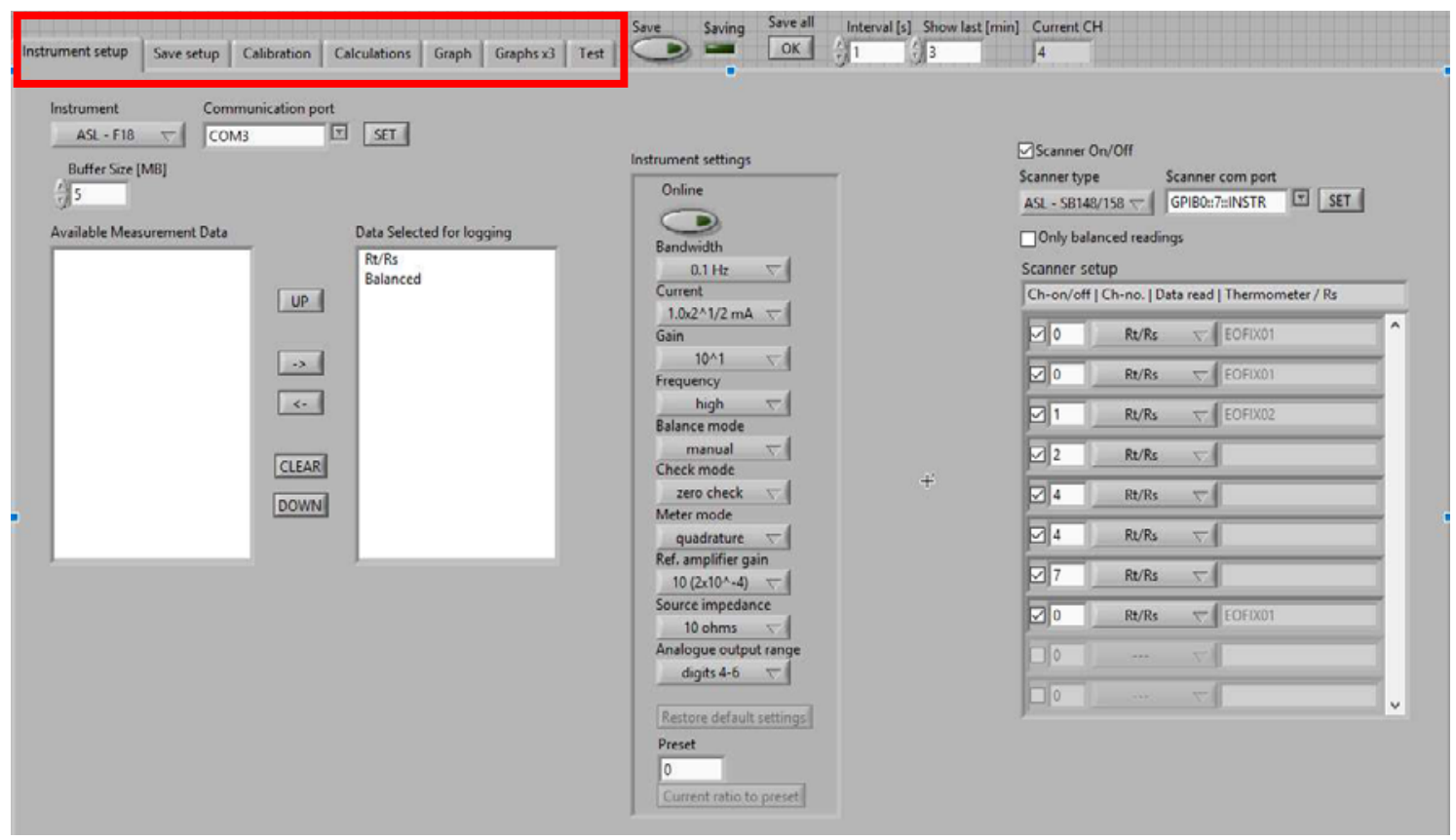

Figure 4. The example of the instrument setup windowin the case of measurements by using platinum resistance thermometers connected to the thermometry resistance bridge. Available settings categories are highlighted red.

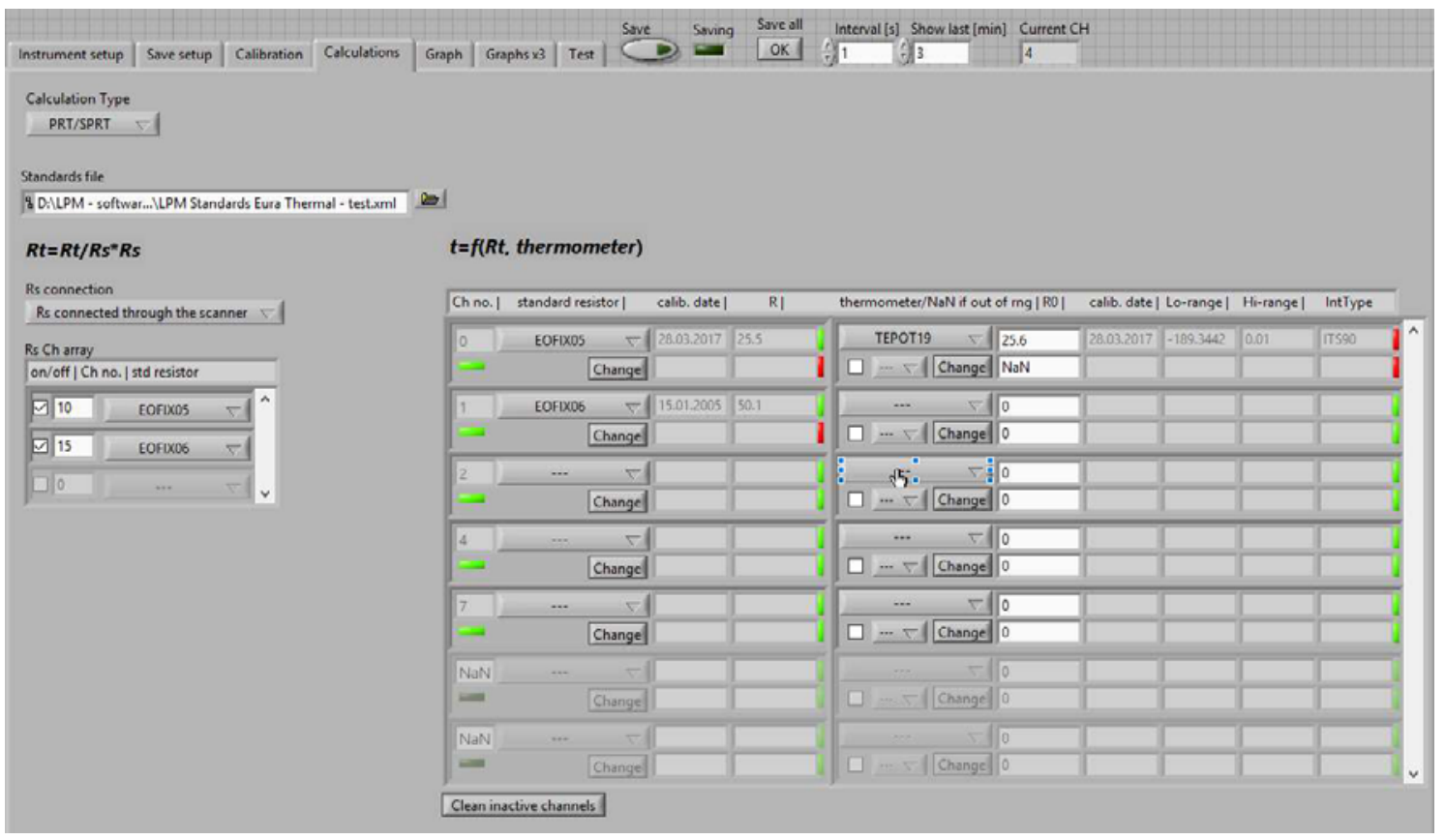

Figure 5. The example of calculation window in the case of measurementsby using platinum resistance thermometers connected to the thermometry resistance bridge.

\section{Conclusion}

The new software described is currently under test in the Laboratory for Process Measurement and will be used for the intercomparison of primary realizations of the fixed points of silver according to the ITS-90 temperature scale in the scope of the EMPIR project Eura-Thermal. The testing will be performed with the thermocouples connected to the high precision multimeter as well as with the standard platinum resistance thermometer connected to the thermometry resistance bridge. It is 
planned to use the same software in other laboratories participating in the intercomparison. In this way, the software will be verified through the intercomparison results. In order to avoid biases of the results that could be potentially caused by the software itself, several laboratories will still use their already validated data acquisition techniques.

Acknowledgments: This work is funded by the European Metrology Programme for Innovation and Research (EMPIR) and national metrology research program.

\section{References}

[1] H. Preston-Thomas, The International Temperature Scale of 1990 (ITS-90), Metrologia 27, 3-10 (1990)

[2] BIPM, Supplementary Information for the International Temperature Scale of 1990, Pavillon de Breteuil, F-92312 Sevres, 1997, ISBN 92-822-2111-3 